\title{
Geographical Distribution of HIV-patients with Respect to HIV-treatment Units in Cameroon: A Cross-sectional Study
}

\author{
André Pascal Goura ${ }^{1,}$, , Benjamin Azike Chukuwchindun ${ }^{2}$, Martin Ndinakie Yakum ${ }^{1}$, \\ Joliette Azakoh Nguefack ${ }^{3}$, Paméla Ekeme Lonbe ${ }^{4}$, Jérôme Ateudjieu ${ }^{1,5,6}$ \\ ${ }^{1}$ Meilleur Accès aux Soins de Santé, Yaoundé, Cameroon \\ ${ }^{2}$ Meilleur Accès aux Soins de Santé, Kousseri, Cameroon \\ ${ }^{3}$ Meilleur Accès aux Soins de Santé, Douala, Cameroon \\ ${ }^{4}$ Department of Law and Political Sciences, University of Dschang, Dschang, Cameroon \\ ${ }^{5}$ Division of Health Operational Research, Cameroon Ministry of Public Health, Yaoundé, Cameroon \\ ${ }^{6}$ Faculty of Medicine and Pharmaceutical Sciences, Department of Public Health, University of Dschang, Dschang, Cameroon
}

\section{Email address:}

gouraandrpascal@yahoo.fr (A. P. Goura), azike21@yahoo.fr (B. A. Chukuwchindun), martinyakum@yahoo.com (M. N. Yakum), julia.nguefack@yahoo.fr (J. A. Nguefack), paekeme@yahoo.fr (P. E. Lonbe), jateudj@yahoo.fr (J. Ateudjieu)

${ }^{*}$ Corresponding author

\section{To cite this article:}

André Pascal Goura, Benjamin Azike Chukuwchindun, Martin Ndinakie Yakum, Joliette Azakoh Nguefack, Paméla Ekeme Lonbe, Jérôme Ateudjieu. Geographical Distribution of HIV-patients with Respect to HIV-treatment Units in Cameroon: A Cross-sectional Study. International Journal of HIV/AIDS Prevention, Education and Behavioural Science. Vol. 5, No. 1, 2019, pp. 59-67.

doi: 10.11648/j.ijhpebs.20190501.18

Received: March 20, 2019; Accepted: April 25, 2019; Published: May 20, 2019

\begin{abstract}
The treatment of HIV-patients is a key component to HIV/aids control strategies. Since 2007, Cameroon is treating HIV-patients for free within decentralized treatment units created in functional health districts. This study aimed to map the geographical distribution of HIV-patients with respect to that of treatment units in Cameroon. We conducted a cross-sectional study in which functional health districts with HIV-treatment units were exhaustively sampled to map the local access to antiretroviral care in the Cameroon West region. Patients from these units were randomly selected and recruited during their monthly period of receiving antiretroviral drugs. Four hundred and seventy-two patients were included. The mean age of participants was $42( \pm 10)$ years with a sex ratio male/female of $1 / 3$. Fourteen units were distributed in 09 health districts (45\% coverage) and 11/20 districts had no Treatment unit. Sixty two percent (294/472) of participants resided in the health district of their screening and 65\% (308/472) were follow up in the health district of residence. Nine of ten patients resided in their treatment health region. Less than $10 \%$ of patients travel from health districts with no HIV-treatment unit. Close to $1 / 5$ (74/382) patient migrated from local health district with treatment unit to another local health district for follow up. Second line treatment was not available except in one public and one private treatment unit. The distribution of HIV-treatment units is strongly linked to the geographical distribution of HIV-patients across health districts. We therefore believe that the creation of treatment units in health districts still lacking them can significantly increase screening and treatment of patients in this region.
\end{abstract}

Keywords: Distribution, Residence, HIV-treatment Unit, Health District, West-Cameroon

\section{Background}

The human immunodeficiency virus is a high public health concern today in the world. Considerable clinical and operational findings have been made and are still ongoing to better understand and fight the disease. Among these findings, effective medication using HIV-antiretroviral molecules in appropriate protocols is known to be successful both for the treatment of HIV-infected individuals and the prevention of the disease [1]. Given these clinical 
achievements, these drugs are widely recommended by the United Nations together with the global health challenges as key control strategy to fight against HIV/AIDS [2]. To appropriate and meet these challenges, countries develop, adopt, support and fund various actions together with WHO recommendations to scale-up sustainable access to HIVtreatments for targeted persons locally [3-5]. To do this, low and middle income countries (LMICs) especially with limited resource health systems, implement the decentralization of ART (HIV-antiretroviral treatment) for HIV-infected patients [6].

WHO reported that more than 14.9 million of people living with HIV were under antiretroviral therapy worldwide, including 13.5 million (more than 90\%) in low- and middle-income countries and this was only $40 \%$ of people living with HIV [7]. In the other hand, the availability of therapeutic protocols in Africa remains the lowest meanwhile this part of the world shelters more than $90 \%$ of the ART (Antiretroviral treatment) needs [8,9]. Like many countries, Cameroon adopted this system as one of the strategic axes of its national policy to control HIV through the creation and extension of care units since access to ART was made free in 2007 [10, 11]. This strategy was in direct line with that of the international comity to effectively treat $90 \%$ of diagnosed persons in order to make the viral load undetectable and thus control the transmission of the virus $[12,13]$, that is why Cameroon national strategic plan for fight against HIV through its first objective aligns with the document "Vision 2035" adopted efficient medical care to PLHIV as main challenge $[11,14]$. The national decentralized policy for the therapeutic follow up of HIV patients has at the central level a National AIDS Control Committee which is in charge of planning, partnership and resources mobilization, and hospitals Reference for the therapeutic follow-up of patients. In regions, we have Regional Technical Groups responsible for technical coordination and support to district, but also provided with specialized treatment centers. At Health District, we find treatment units (TU) that receive newly diagnosed patients and provide them with first-line antiretroviral treatment. Generally, this TU is under the responsibility of a general practitioner with nurses involved in the overall follow-up of the patients.

In Cameroon, as in many sub-Saharan countries, the prevalence of HIV is still high $(4.3 \%$ in 2011$)$ as the number of new infections keep increasing (6 new infections per hour) $[15,16]$. Sexual activity remains as important as the fertility index among PLHIV. multisexual partnership and the desire of having a child which is a warning signal for rapid and precise intervention are also important [15]. In the other hand all regions of the country are affected by the pandemic with prevalence that varies from region to region; but more, the country had an inequitable distribution of care units from one region to another as well as care offer varies with the health pyramid, which can highly cause patients to migrate and face resultant difficulties.

In the last decade, the number of care units created has considerably increased over time to catch up on the increasing number of HIV cases in the country. 163 treatment units ( $61 \%$ coverage of health districts) were functional throughout the country and the active line was estimated to 13,147 patients in the beginning of 2015 for the study area. The health system is weak and resources are still limited; This has serious implications on health programs despite developed policies and strategies [16]. As evidence, all HIV-screened patients do not have access to treatment because of limited resources. There is then much to evaluate as far as quality, availability of care and accessibility to reference structures are concerned [17, 18]. We believe that due to inadequate global care, many patient do not take their treatment where they live for one reason or the other and they move from one health district to another causing an increase of lost to follow up patients. What is the proportion of patients taking treatment to the nearest treatment unit to their residence? The objective of this study was to describe the distribution of PLHIV with respect to their treatment unit.

\section{Materials and Methods}

\subsection{Study Design}

We conducted a cross-sectional descriptive study from June 2015 to February 2016. Functional health districts with HIV-treatment units were exhaustively sampled for the mapping of the local access to antiretroviral care in the region. Consenting patients of these units were randomly selected, and submitted to a face to face interview in other to describe their geographical distribution around care units. They were recruited during their monthly period of receiving antiretroviral drugs.

\subsection{Study Site}

The Cameroon West region was our study area. The epidemiological profile as in Figure 1 showed a general HIV prevalence of $2.8 \%$ from the recent national health demographic survey, with considerable number of female sex workers. Curiously, this prevalence was 3 times lower than those of the three surrounding and had better access to healthcare $[19,20]$. 


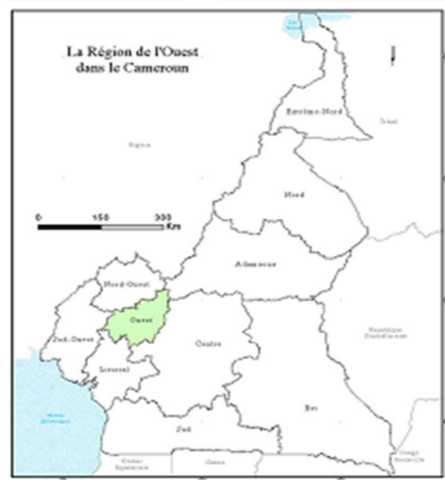

Légende

District de santé

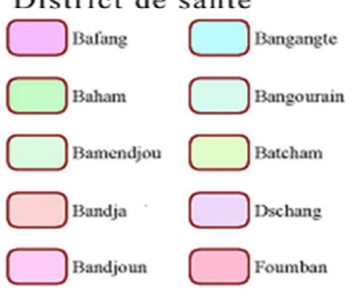

Limite d'unité de santé $\sim$ Limite d'Aire de santé $\simeq$ Limite de District de santé $\simeq$ Limite de Région

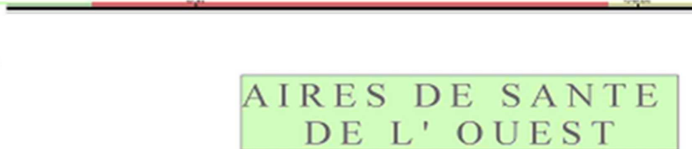

$\{$ Management Unit
Advanced treatment Unit

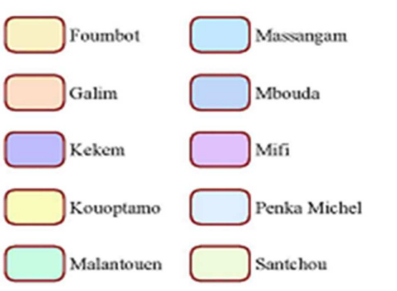

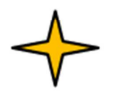

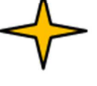

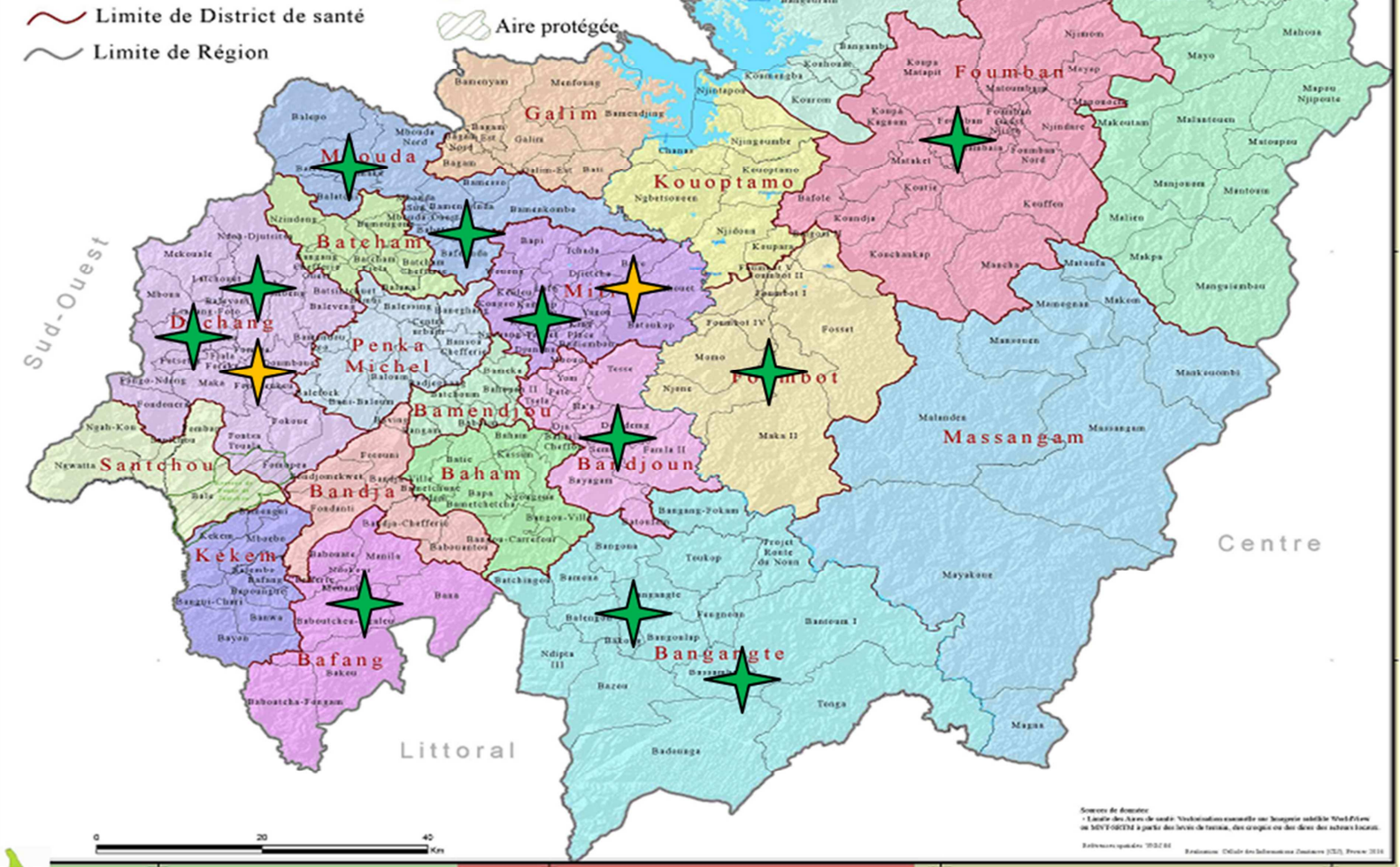

Figure 1. Cameroon map and the West region location.

\subsection{Sampling and Sample Size}

All functional health districts in the region with at least one unit offering care to people living with HIV were targeted. Public and private units were exhaustively selected. The study population was HIV patients follow up in any of the regional treatment units. Eligible patients had to be registered in the active line of the health facility for therapeutic follow-up for at least 06 consecutive months with an officially opened file on his/her behalf in the care unit. Participants were randomly selected in targeted units from the patient records and missing or absent respondents were replaced. The sample size was estimated from the table 1. a formula of the WHO Practical Manual of Sample Size determination in Health Studies [21]. We considered the following parameters: the regional HIV prevalence $(\mathrm{p}=2.8 \%)$, a $95 \%$ level of significance $(z=1.96)$, a precision $d=0.05$ and a non-response rate of $10 \%$. The minimum sample size 
required for the study was 419 participants and the number of patients sampled in each unit was estimated proportionally to its size in the total active line of the region.

\subsection{Data Collection}

Data were collected only from consenting patients. This was done using a questionnaire administered in face to face interview in a secret box room arranged for this purpose. Data included demographic, patients' residence and the treatment centre related information.

\subsection{Data Analysis}

Data were keyed and analyzed using software Epi-info (version 7.1) to estimate proportions. MS Excel and MS Word 2007 were used for graphs and tables.

\section{Results}

\subsection{Characteristics of the Study Population}

Four hundred and seventy-two patients from 08 functional treatment units participated to this survey. The estimated active line was 13.147 patients for the whole region. The mean age of participants was $42(32-52)$ years with a sex ratio male/female of $1 / 3$. About $51.9 \%(245 / 472)$ of patients had at least attained high school and 69.1\% (326/472) were Christians, compared with 20.1\% (95/472) of Muslim religion. Even if $40 \%(189 / 472)$ of this sample is married to the monogamy regime, $25.2 \%$ (119) is made of widowers. We found a median fertility rate of 03 children per patient. Figure 2 tells more about the ethnographic origins of participants.

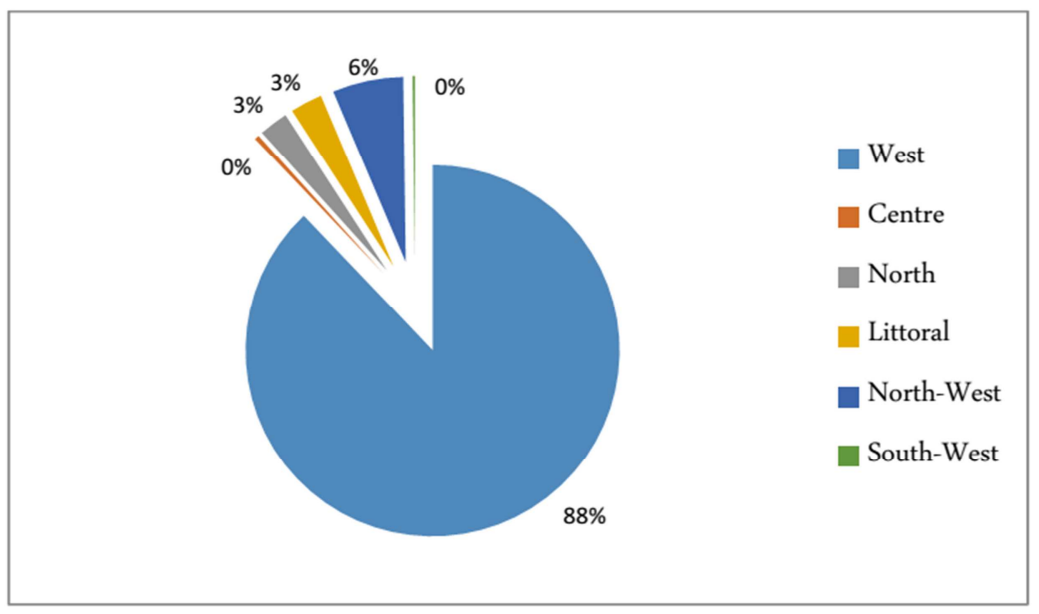

Figure 2. Ethnographic distribution of participants.

\subsection{Operation of HIV Treatment Unit in West Region}

The local management of HIV patients stands on a 3 levels system. The peripheral level is implemented in districthospital-like health facilities which are provided with treatment unit (TU) and staff. These are operational units for the first level of reference in the system. Nine of the 20 health districts ( $45 \%$ coverage) were provided with at least a TU for a total of 14 TU. The Bafoussam regional hospital (public) and the DREAM private centre (Dschang) go with intermediate level for patient observation, references, specialized care to patients. These are Advanced Treatment Centres (ATCs). Though first line patients are here follow up, these centers had as mission to manage treatment failures and cases of resistance to first line antiretroviral treatments. The government regional staff had also to supervise attached Treatment units and update them with new skills. At the top, the central level with Ministry of Public Health was for supervision and health strategies and policy statements. The eligibility of patients to HIV therapy respected to the national guideline. Some entered in the active line through screening, some through transfer and medical reference. Patients received their drugs after check up by the medical practitioner.

Many antiretroviral molecules were used for patient treatment in this region. For the first line, 04 protocols including 2 NRTI +1 NNTI (nucleotide reverse transcriptase inhibitor and non-nucleotide reverse transcriptase inhibitor), the IP reserved for the ATC only. In adults and adolescents, first-line ART includes Zidovudine, Lamivudine, Efavirenz, Nevirapine and Stavudine. The second line treatment was accessible only in the Bafoussam ATC and the Dschang St Vincent de Paul Hospital on medical reference. As regards to lab tests, CD4 count, Viral load were available only in ATCs. Other routine examinations (BC, ASAT, ALAT, Creatine, Amylasemia, Triglycerides, Cholesterol, fasting glucose, etc) were available in district hospitals.

\subsection{Access to Antiretroviral Care for Patients in Cameroon Western Region}

From the twenty (20) functional health districts of this region 09 (45\% coverage) were provided with at least one TU as mapped in Figure 3. One health district hosted three TUs, 03 had two TUs and 05 had one. A total of 14 units were functional to deliver HIV care to patients, thus $1 \mathrm{TU}$ for 939 patients. Four of the $14(28.6 \%)$ were logged in private health facilities. Table 1 summarizes the distribution of patients in health facilities and their proportions in the total active line of the region. 


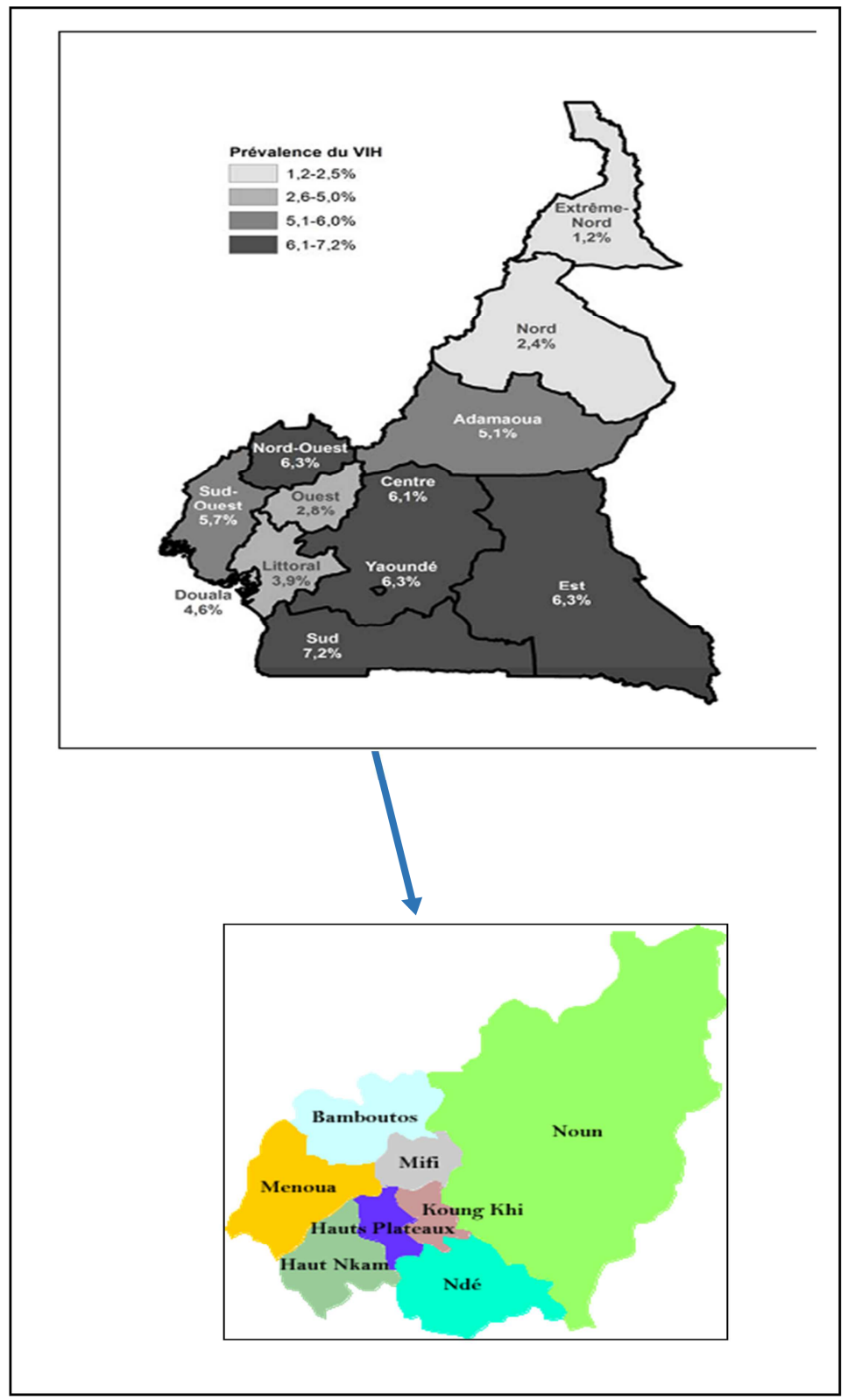

Figure 3. West regional health map and geographical distribution of treatment units.

Table 1. General distribution of HIV patients in health districts.

\begin{tabular}{llllll}
\hline $\mathbf{N}^{\circ}$ & Health District & ATC/TU location & Type of HF & AL 2015 & Proportion in the total AL (\%) \\
\hline 01 & BAFANG & ALDH Bafang & Privat & 1012 & 7.7 \\
02 & BANDJOUN & Bandjoun DH & Public & 70 & 0.5 \\
03 & BANGANGTE & Bangante DH & Public & 323 & 2.5 \\
& & Bangoua & Confessionnal & 423 & 3.3 \\
04 & \multirow{2}{*}{ DSCHANG } & Dschang DH & Public & 899 & 6.9 \\
& & DREAM Centre & Confessionnal & 1116 & 8.5 \\
05 & FOUMBAN & UTC University & School & 35 & 0.2 \\
06 & FOUMBOT & Foumban DH & Public & 1820 & 13.8 \\
07 & MALANTOUEN & Foumbot DH & Public & 1120 & 8.5 \\
08 & MBOUDA & Malantouen DH & Public & 257 & 2 \\
& & Mbouda DH & Public & 1243 & 9.4 \\
09 & MIFI & ALDH Mbouda & Privat & 261 & 2 \\
Total & & Police MC & Public & 222 & 1.6 \\
\hline
\end{tabular}

UTC $=$ University Treatment Centre, DH= District Hospital, $\mathrm{RH}=$ Regional Hospital 


\subsection{Geographical Distribution of Patient Around Treatment Units}

Close to $23 \%(107 / 472)$ of patients were diagnosed out of the study region. Health districts with at least one TU diagnosed $73 \%(345 / 472)$ of patients under treatment. Bafoussam (regional capital) diagnosed $134(28 \%)$ patients and $37 \%(40 / 107)$ of those who were screened out of the region came from Douala. Sixty two percent (294/472) resided in the health district of screening. See Figure 4 for distribution per health district. About 97\% (460/472) of participants were diagnosed in a health facility and the remaining $3 \%$ in mobile caravan and at home.

With respect to treatment units, $65 \%(308 / 472)$ of sample patients were follow up in their health district of residence. See Figure 3 for distribution per health district. 81\% (382/472) were residing in the study region with at least one treatment unit in their health district of residence. Close to $1 / 5(74 / 382)$ patient migrated from local health district with treatment unit to another local health district for follow up as in Figure 4 and Figure 5. Overall, 8\% (40/472) resided in surrounding regions but were normally follow up in the study region.

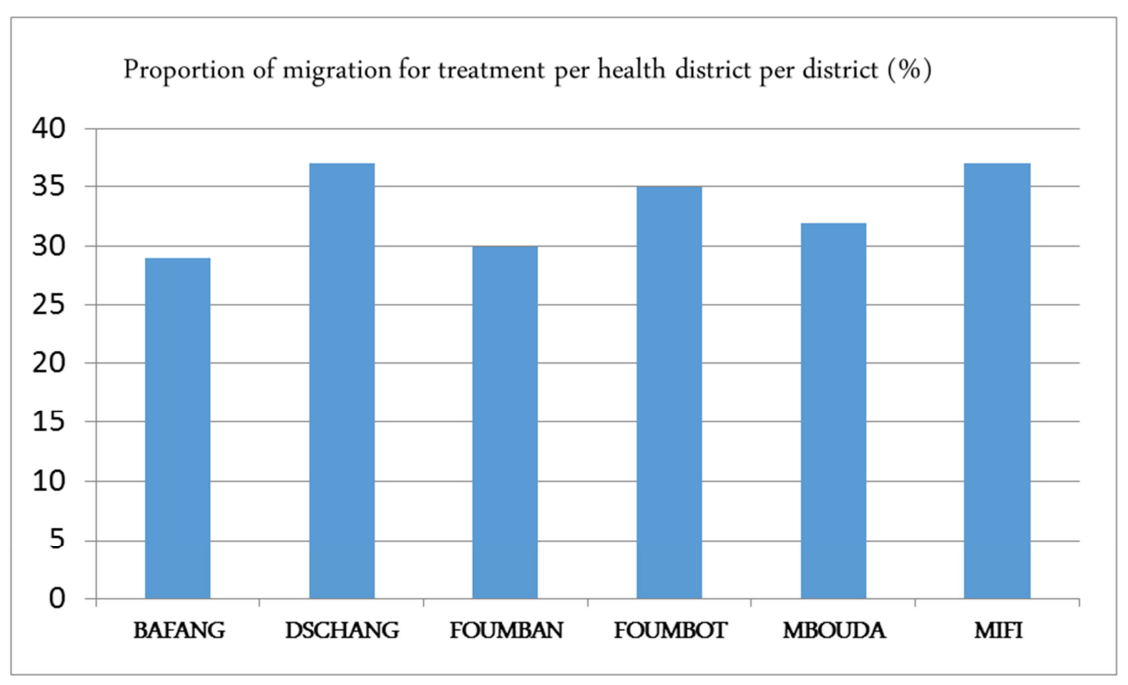

Figure 4. Proportion of migrations for treatment sake per health district with care units.

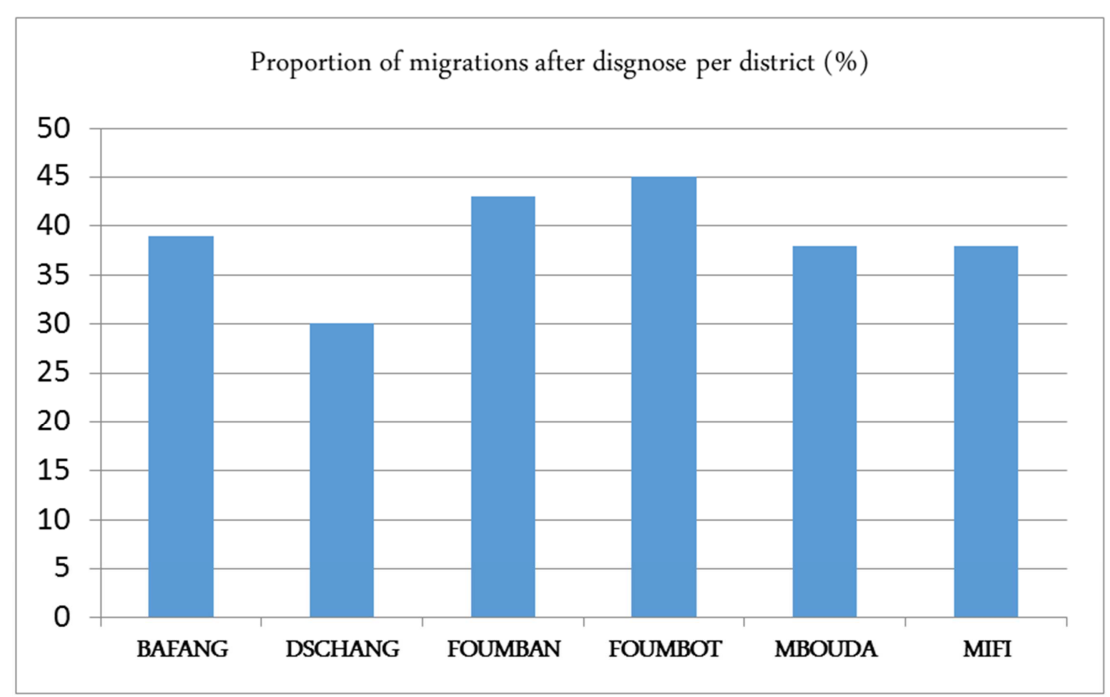

Figure 5. Proportion of migrations per health district after patient is diagnosed.

\section{Discussion}

This paper attempts to describe the access to ART and the geographical distribution of HIV infected patients under treatment with respect to treatment units, thus to better understand the influence of TU in a given health area.

The West is the smallest of the 10 regions of Cameroon and it counted at the time of this study 20 functional health districts of which only 09 had at least one functional TU (45\% coverage). Sixty two percent (294/472) of participants resided in the health district of their screening. With respect to TUs, $65 \%$ (308/472) of sample patients are follow up in their health district of residence. Close to $1 / 5(74 / 382)$ patient migrated from local health district with treatment unit to 
another local health district for follow up. About $72 \%$ (274/382) of participants were follow up in the diagnose health districts. This tells us how limited is access ART in this area of the country and how it does not yet meet with WHO standards on decentralization of ART to HIV patients [22]. Disparities are recorded at all levels, both between regions, urban and rural areas. Resources are limited to insure better care to patients meanwhile health facilities are the main gate for HIV patient recruitment and detection. Regardless to the quality of patient management, the low coverage of TU in Cameroon West region does not match at all with the generalization of the pandemic. Eleven of the 20 health districts had no one treatment centre and they were even less represented in the active line. We can then assume that, given the population of this region that year, about $28 \%$ of them were supposed not to have direct access to ART care from their residing health districts; not considering the fact that only divisional head cities were provided with a care unit in districts with access to ART. It is therefore not surprising that from this study, recruited patients were most of them inhabitants of the region and they resided mostly in health districts with at least one care unit. The presence of a TU for care delivery to HIV patients in a health district determines the recruitment rate of HIV subjects in the active line since $65 \%$ of them are follow up in their districts of residence. After they are diagnosed, they are committed to take their first treatments where they are diagnosed if there be a care unit; otherwise, they can be exposed to long distance displacements which can later become a serious limitation factor to access to adequate early treatment. Regardless to the therapeutic histories and difficulties in accessing treatment in units, patient distribution throughout the region is highly dependent on the distance between the patient residence and the follow-up unit $[23,24]$. Even for the local health system, it is clearly known that the more health care is closer to populations the better improved is their access, especially the most vulnerable. The context of poverty and developing countries does not promote greater integration and adherence of remote populations to health interventions, yet they also carry the burden of current health problems and cannot achieve results as good as those of urban areas [25, 26]. The decentralization of access to antiretroviral treatment through the creation of TU in Cameroon health districts made it possible to state that this health policy is an increasing factor for the detection, recruitment and control of HIV patients in the study region $[23,25]$.

It is necessary to go toward remote populations with healthcare to break the silence of the districts weakly or not represented; otherwise, the epidemic will silently continue to spread and efforts made so far will be in vain meanwhile the results would have been better even in a context of limited resources [27-29]. HIV has also become a concern in rural areas, the best interventions should also target these sometimes ignorant populations. The integration approach would allow the primary health care system of the public sector to test more HIV patients, place more patients on ARVs faster and more efficiently, thereby reducing the number of patients lost to follow-up and achieving greater geographical coverage of care versus vertical model [28, 30, 31]. It is therefore clear that the low representation of other districts in the region can be explained by the low level of recruitment of PLHIV and the geographical inaccessibility of these populations to ART $[23,32]$. Creating more care units in these districts would not only facilitate easier access to ART, but also a large recruitment of PLHIV with as immediate consequence the control of this target population and even a reduction in long-term of health expenditure [23, 27, 28].

Migrating patients should certainly be either those coming from distant districts and who could not overcome the distance barrier and because of limited resources finally returned to their residence districts for ART care, those under second-line treatment (effective only to the ATC of Bafoussam and Dschang), those having enough resources to be follow up by specialists in the biggest cities of the country or finally those looking for discretion as stipulated by many studies [31, 33, 34]. Districts without any Treatment units are less represented in the active line than surrounding region, surely because most of them (72\%) are follow up where they are diagnosed. The representativeness of Littoral, Adamawa, Centre and Northwest regions in our study is surely linked to the fact that this region shares its geographical borders with them, thus a simplified access to West units as compared to the main units in their regions [23, 25]. A stronger representativeness of patients from Littoral region can be explained by the overloaded Treatment units found in this region of the country compared to their insufficient supply of ART, added to difficulties these patients encounter to obtain their treatment and to ensure a better therapeutic monitoring $[31,32,35-37]$. That is why there is a considerable proportion of non residence in health districts like MIFI and Dschang, immediately connected to Littoral with highway routes. In these large metropolises, medical promiscuity gives way to poor patient follow-up, coupled with other factors such as drug shortages, the cost of certain services supposedly free, stigmatization and non-respect of patient confidentiality $[35,38,39]$.

It is no longer necessary to demonstrate that the presence of a unit providing care to HIV persons guarantees the accessibility to indigenous PLHIV and thus could considerably lead to a better control of PLHIV and somehow reduce loss sight to follow up patients in the Cameroon western region [23, 26, 28, 30, 31].

The shortcomings of this research project include the fact that HIV children were not involved given the fact they are managed by another program which is the Prevention of mother-to-child Transmission of HIV (PMTCT). Their geographical distribution within health districts could influence that of adults follow up in classic Treatment units. Another limit is that missing patients to the ramdom selection were simply replaced, so we think that high personalities living with HIV could not be interviewed even when they could be randomly selected from the list of the active line. This is because it is difficult and even impossible to find 
them lining with others routinely and during this survey. Notwithstanding, regarding the study design and the quality of data collected, data source and trained surveyors to collect these data, we believe that the results of this study can be exploited and even inferred to the whole region.

\section{Conclusion}

The distribution of ART units strongly influence the geographical distribution of HIV patients across health districts in the Cameroon West region. The national policy of the decentralization of access to antiretroviral therapy can seriously improve the recruitment of patients and empower the control of the active line. Access to antiretroviral therapy is very limited in the western region of Cameroon. However, the distribution described in this study targets screened patients only; it is therefore necessary to look into "silent" districts to understand how HIV patients are managed especially in a context of high prevalence. Health authorities are urgently challenged to strengthen strategies to expand the supply of adequate care to patients living with HIV.

\section{Acknowledgements}

We sincerely thank:

1. The Regional Delegation of Public Health for the West region of Cameroon for its administrative support.

2. All health district and the treatment unit staff involved in this study for their collaboration and facilitation.

3. All the surveyors from Dschang, Foumbot and DREAM Center Treatment units for data collection.

4. All participants for their collaboration.

\section{Ethics Approval and Consent to Participate}

Ethical clearance was obtained from the Cameroon National Research Ethical Committee before the implementation of the study $\left(\mathrm{N}^{\circ}\right.$ 2014/12/666/CE/CNERSH/SP). All participants were well informed and they consented with their signature to participate. For minor $($ Age $<21)$, the consent was given by their guardians and the assent given by the participant.

\section{Competing Interests}

The authors declare that they have no competing interests.

\section{Funding}

The project was funded by the investigator and partially supported by M.A. SANTE.

\section{Author's Contribution}

APG contributed in conceiving the study and design, organized and coordinated data collection, keyed, cleaned and analyzed data, drafted the manuscript and coordinated its review.

JA contributed in the study conception and design, drafted the manuscript and coordinated its review.

PEL contributed data entry.

APG, JA, MNY, BAC, PEL, and ACB contributed in revising the manuscript.

All authors read and approved the final manuscript

\section{References}

[1] H. F. Günthard et al., «Antiretroviral Treatment of Adult HIV Infection: 2014 Recommendations of the International Antiviral Society-USA Panel», JAMA, vol. $312, \mathrm{n}^{\circ} 4$, p. 410425, juill. 2014.

[2] V. D. Lima et al., «Progress towards the United Nations 90 90-90 and 95-95-95 targets: the experience in British Columbia, Canada», J. Int. AIDS Soc., vol. 20, $\mathrm{n}^{\circ} 3$, nov. 2017.

[3] M. Yotebieng et al., «Research priorities to inform "Treat All" policy implementation for people living with HIV in sub Saharan Africa: a consensus statement from the International epidemiology Databases to Evaluate AIDS (IeDEA)», J. Int. AIDS Soc., vol. 22, $\mathrm{n}^{\circ} 1$, janv. 2019.

[4] J. Smith, «Europe's Shifting Response to HIV/AIDS», Health Hum. Rights, vol. 18, n 2, p. 145-156, déc. 2016.

[5] K. Porter et al., « Substantial Heterogeneity in Progress Toward Reaching the 90-90-90 HIV Target in the WHO European Region », J. Acquir. Immune Defic. Syndr. 1999, vol. $79, \mathrm{n}^{\mathrm{o}} 1$, p. $28-37$, sept. 2018.

[6] M. L. Scanlon et R. C. Vreeman, «Current strategies for improving access and adherence to antiretroviral therapies in resource-limited settings», HIVAIDS Auckl. NZ, vol. 5, p. 117, janv. 2013.

[7] OMS, «STRATEGIE MONDIALE DU SECTEUR SANTE CONTRE LE VIH 2016-2021». juin-2016.

[8] G. Ndziessi et al., «Changes in sexual activity and risk behaviors among PLWHA initiating ART in rural district hospitals in Cameroon -- data from the STRATALL ANRS 12110/ESTHER trial», AIDS Care, vol. 25, n 3, p. 347-355, 2013.

[9] OMS, «OMS | VIH/sida», WHO, 2015. [En ligne]. Disponible sur: http://who.int/mediacentre/factsheets/fs360/fr/. [Consulté le: 28-oct-2015].

[10] «Current World Literature», Curr. Opin. HIV AIDS, vol. 8, n 1, p. 75, janv. 2013.

[11] Cameroon Ministry of Public Health, «National strategic plan for Fight against AIDS and STD 2014-2017». 2013.

[12] ONUSIDA, «90-90-90: Une cible ambitieuse de traitement pour aider à mettre fin à l'épidémie du sida». 2014.

[13] J. S. Mukherjee, D. Barry, R. D. Weatherford, I. K. Desai, et P. E. Farmer, «Community-Based ART Programs: Sustaining Adherence and Follow-up», Curr. HIV/AIDS Rep., vol. 13, $\mathrm{n}^{\circ}$ 6, p. 359, 2016. 
[14] MINEPAT, «Cameroun Vision 2035». Cameroon, 2009.

[15] G. Ndziessi et al., «Changes in sexual activity and risk behaviors among PLWHA initiating ART in rural district hospitals in Cameroon -- data from the STRATALL ANRS 12110/ESTHER trial», AIDS Care, vol. 25, n 3, p. 347-355, 2013.

[16] «EDSMICS2011.pdf».

[17] K. A. Hoffman et al., «[Barriers to implementing screening, brief intervention and referral to treatment for substance use in HIV/AIDS health services in Peru]», Rev. Peru. Med. Exp. Salud Publica, vol. 33, $\mathrm{n}^{\circ}$ 3, p. 432-437, sept. 2016.

[18] A. F. Aghokeng et al., «Inaccurate Diagnosis of HIV-1 Group $\mathrm{M}$ and $\mathrm{O}$ Is a Key Challenge for Ongoing Universal Access to Antiretroviral Treatment and HIV Prevention in Cameroon», PLoS ONE, vol. 4, n 11, nov. 2009.

[19] CAMEROUN, «Enquête Démographique et de Santé et à Indicateurs Multiples». INS, MINEPAT, MINSANTE, ICF International, 2011.

[20] E. N. Mziray, «Mapping and size estimation of female sex workers in Cameroon: to inform HIV program design and implementation - executive summary», The World Bank, 108492, août 2016 .

[21] Lwanga S. K., Lemeshow S., et Organization W. H., «Sample size determination in health studies: a practical manual», Díermination de la taille d' un čhantillon dans les t'udes sanomtriques: manuel pratique, 1991.

[22] A. Dutta, C. Barker, et A. Kallarakal, «The HIV Treatment Gap: Estimates of the Financial Resources Needed versus Available for Scale-Up of Antiretroviral Therapy in 97 Countries from 2015 to $2020 », P L o S$ Med., vol. 12, n ${ }^{\circ} 11$, nov. 2015.

[23] S. S. Solomon et al., «Design of the Indian NCA study (Indian national collaboration on AIDS): a cluster randomized trial to evaluate the effectiveness of integrated care centers to improve HIV outcomes among men who have sex with men and persons who inject drugs in India», BMC Health Serv. Res., vol. 16, $\mathrm{n}^{\mathrm{o}} 1$, p. 652, nov. 2016.

[24] F. Vogt et al., «Decentralizing ART supply for stable HIV patients to community-based distribution centres: Programme outcomes from an urban context in Kinshasa, DRC», $J$. Acquir. Immune Defic. Syndr. 1999, oct. 2016.

[25] S. Loubiere et al., «Decentralization of HIV care in Cameroon: increased access to antiretroviral treatment and associated persistent barriers», Health Policy Amst. Neth., vol. $92, \mathrm{n}^{\circ} 2-3$, p. $165-173$, oct. 2009.

[26] S. Boyer et al., «Scaling up access to antiretroviral treatment for HIV infection: the impact of decentralization of healthcare delivery in Cameroon», AIDS Lond. Engl., vol. 24 Suppl 1, p. S5-15, janv. 2010.

[27] N. B. Njozing, S. S. Miguel, P. M. Tih, et A.-K. Hurtig, «Assessing the accessibility of HIV care packages among tuberculosis patients in the Northwest Region, Cameroon», BMC Public Health, vol. 10, p. 129, mars 2010.

[28] J. Pfeiffer et al., «Integration of HIV/AIDS services into African primary health care: lessons learned for health system strengthening in Mozambique - a case study», J. Int. AIDS Soc., vol. 13, p. 3, janv. 2010.

[29] S. Boyer et al., «Performance of HIV care decentralization from the patient's perspective: health-related quality of life and perceived quality of services in Cameroon», Health Policy Plan., vol. 27, nº 4, p. 301-315, juill. 2012.

[30] S. Rasson et al., «Decentralization of access to antiretroviral therapy in Cameroon: correlates of HIV physicians' knowledge in HIV care», Antivir. Ther, vol. 16, no 3 , p. 423428, 2011.

[31] B. Rachlis et al., «Facility-Level Factors Influencing Retention of Patients in HIV Care in East Africa», PLOS ONE, vol. $11, \mathrm{n}^{\circ} 8$, août 2016 .

[32] M. Saki, S. Mohammad Khan Kermanshahi, E. Mohammadi, et M. Mohraz, «Perception of Patients With HIV/AIDS From Stigma and Discrimination», Iran. Red Crescent Med. J., vol. $17, \mathrm{n}^{\mathrm{o}} 6$, juin 2015 .

[33] I. Sieleunou, M. Souleymanou, A.-M. Schönenberger, J. Menten, et M. Boelaert, «Determinants of survival in AIDS patients on antiretroviral therapy in a rural centre in the FarNorth Province, Cameroon», Trop. Med. Int. Health, vol. 14, $\mathrm{n}^{\mathrm{o}} 1$, p. 36-43, janv. 2009.

[34] K. A. Hoffman et al., «[Barriers to implementing screening, brief intervention and referral to treatment for substance use in HIV/AIDS health services in Peru]», Rev. Peru. Med. Exp. Salud Publica, vol. 33, n 3, p. 432-437, sept. 2016.

[35] F. Marcellin et al., «Determinants of unplanned antiretroviral treatment interruptions among people living with HIV in Yaoundé, Cameroon (EVAL survey, ANRS 12-116)», Trop. Med. Int. Health, vol. 13, $\mathrm{n}^{\circ}$ 12, p. 1470-1478, déc. 2008.

[36] J. J. Olney et al., «Evaluating strategies to improve HIV care outcomes in Kenya: a modelling study», Lancet HIV, oct. 2016.

[37] GIP ESTHER du CHU de Nancy, ««ATELIER DE RENFORCEMENT DES CAPACITES DES MEMBRES DES CTA ET UPEC SOUS L'EGIDE DU GIP ESTHER DU 16 AU 18 JANVIER 2012.», Rapport général», Hôpital Régional de Garoua, CAMEROUN, MINSANTE, janv. 2012.

[38] Y. B. Marcel, «ITINERAIRES THERAPEUTIQUES D'UN MALADE DECEDE DU SIDA A ABIDJAN (CÔTE D'IVOIRE)», Eur. Sci. J. ESJ, vol. 8, nº 13, juin 2012.

[39] S. Boyer et al., «Financial barriers to HIV treatment in Yaoundé, Cameroon: first results of a national cross-sectional survey», Bull. World Health Organ., vol. 87, n 4, p. 279-287, avr. 2009. 